Short communication

\title{
Mechanical properties of proton-conducting sulfonated aromatic polymer membranes: Stress-strain tests and dynamical analysis
}

\author{
E. Sgreccia ${ }^{\mathrm{a}, \mathrm{b}}$, J.-F. Chailan ${ }^{\mathrm{c}}$, M. Khadhraoui ${ }^{\mathrm{a}}$, M.L. Di Vona ${ }^{\mathrm{b}, *}$, P. Knauth ${ }^{\mathrm{a}, * *}$ \\ a Université de Provence-CNRS: UMR 6264 Laboratoire Chimie Provence, Centre St Jérôme, Marseille, France \\ b Università di Roma Tor Vergata, Dip. Scienze Tecnologie Chimiche, Roma, Italy \\ c Université du Sud Toulon-Var, MAPIEM (EA 3834), Toulon, France
}

\section{A R T I C L E I N F O}

\section{Article history:}

Received 25 June 2009

Received in revised form

21 September 2009

Accepted 30 September 2009

Available online 23 October 2009

\section{Keywords:}

PEM fuel cells

Polymer electrolytes

Thermomechanical properties

DMA

\begin{abstract}
A B S T R A C T
The mechanical properties of sulfonated aromatic polymers (SAPs: SPEEK and SPPSU) are studied by tensile stress-strain tests and dynamic mechanical analysis (DMA). The elastic moduli are generally above $1 \mathrm{GPa}$ with tensile strength between 25 and $80 \mathrm{MPa}$ and elongation at rupture between 7 and $50 \%$. These properties are consistent with polymers below their glass transition temperature. The glass transition and elastic moduli are strongly increased by thermal treatments of the SAP membranes, due to formation of cross-links between macromolecules. The cross-linking is observed "in situ" during DMA experiments on thermally untreated SPPSU. These data show that previously neglected SAPs might become very interesting PEM fuel cell membranes, if previously thermally treated.
\end{abstract}

(C) 2009 Elsevier B.V. All rights reserved.

\section{Introduction}

Mechanical properties are among the most relevant properties of polymers $[1,2]$. They are specified with the same parameters used for metals, that is elasticity modulus, tensile strength, and ductility [3]. For many polymeric materials, tensile stress-strain tests are employed to determine these mechanical properties [4]. Stress-strain measurements are, however, very sensitive to the experimental protocol, because the mechanical properties of polymers are generally highly sensitive to the nature of the environment, such as presence of water, organic solvents, oxygen and temperature [5-7]. Increasing the temperature induces generally a decrease in elastic modulus, a reduction of tensile strength and an increase of ductility, if no modification of the microstructure, such as partial crystallization, occurs. Very significant changes are observed near the glass transition temperature, where viscous loss strongly increases [8]. Consequently, it is imperative to have consistency in the manner in which stress-strain tests are conducted, using standardized testing techniques.

Dynamical mechanical analysis (DMA) is a complementary characterization technique for polymers widely used now. Here, the samples are submitted to a periodic mechanical strain or stress,

\footnotetext{
* Corresponding author.

** Corresponding author. Tel.: +33 491637 114; fax: +33 491637111.

E-mail address: philippe.knauth@univ-provence.fr (P. Knauth).
}

while the temperature is changed with a constant rate. The storage modulus $E^{\prime}$ (elastic response) and loss modulus $E^{\prime \prime}$ (viscous response) of polymers are measured as a function of temperature. The storage modulus is related to stiffness and the loss modulus to energy dissipation. The $E^{\prime \prime} / E^{\prime}$ ratio, also named $\tan \delta$, is related to mechanical damping [9]. These three parameters vary significantly with temperature and frequency, especially around polymer relaxation phenomena, such as glass transition or sub-glass transition: while the storage modulus decreases, loss modulus and damping show a maximum. These changes in viscoelastic properties are strongly dependent on molecular motions and segmental mobility [10]. Thus, every factor affecting macromolecular mobility, such as ageing [11], crystallinity or small absorbed molecules, leads to significant changes of relaxation processes and global viscoelastic properties of polymers. Dynamic mechanical analysis is therefore very powerful to determine the glass transition temperature $\left(T_{\mathrm{g}}\right)$ of materials and the useful temperature range for application of a mechanically strong polymer membrane. An amorphous polymer may behave like a glass at low temperature, where ductility, expressed as percent elongation at fracture, is generally below $10 \%$, and like a rubbery solid above the glass transition temperature, where viscous behaviour prevails. For intermediate temperatures, the polymer presents viscoelastic mechanical characteristics [2].

Proton-conducting polymer membranes are currently much studied as possible electrolytic membranes for proton-exchange membrane fuel cells (PEMFCs) [12]. Much effort was dedicated to optimizing the proton conductivity [13-15]. However, other prop- 
erties, such as water uptake and retention behaviour at the optimal operation conditions of PEMFC, i.e. around $120^{\circ} \mathrm{C}$ at $25 \%$ relative humidity, are at least as important for application [16-18]. Furthermore, it was pointed out that a correlation exists between the water uptake behaviour of the membranes and their mechanical properties; that is soft membranes tend to swell excessively by sorption of large quantities of water, whereas too strong membranes do not allow sufficient water to be sorbed and the membrane conductivity is too low to be of interest for PEMFC application $[5,19,20]$.

The mechanical properties of proton-conducting polymer membranes are thus a very worthwhile topic for study $[21,22]$. The temperature dependence is of particular importance for application. However, dynamic mechanical properties of such membranes are not extensively studied and very well defined and reproducible experimental protocols must be applied in order to obtain reliable and meaningful results. Furthermore, this technique is used essentially for thermal characterization (i.e. $T_{\mathrm{g}}$ determination), but rarely for combining thermal and mechanical properties of membranes. Recently, several studies deal with the influence of some parameters on viscoelastic properties of proton-exchange membranes. For example, network chemical nature [23,24], membrane treatments [25-27], water uptake [28] or degree of sulfonation [29-31], have been investigated. In this work, we present the mechanical (including elastic modulus, tensile strength and elongation at fracture) and dynamic mechanical properties of sulfonated aromatic polymers (SAPs). The data were obtained by room temperature stress-strain tests and DMA experiments, typically performed between 25 and $250{ }^{\circ} \mathrm{C}$. The polymers include sulfonated poly-ether-ether-ketones (SPEEKs) and sulfonated poly-phenylsulfones (SPPSUs). The influence of a curing treatment of the polymer membranes on their thermomechanical properties is also analyzed.

\section{Experimental}

\subsection{Synthesis and thermal treatment of ionomer membranes}

Sulfonated PEEK (SPEEK) and PPSU (SPPSU) were prepared by reaction of PEEK (Victrex 450P, MW $=38,300$ ) or PPSU (Solvay, $\mathrm{MW}=46,173$ ) with concentrated sulfuric acid at $50^{\circ} \mathrm{C}$ for times between 3 and 5 days, depending on the desired degree of sulfonation. The solution was poured under continuous stirring into a large excess of ice-cold water. After $12 \mathrm{~h}$, the white precipitate was filtered and washed several times with cold water to neutral $\mathrm{pH}$. The sulfonated polymer was then dried at $80^{\circ} \mathrm{C}$ for $12 \mathrm{~h}$. The degree of sulfonation (DS) was evaluated by ${ }^{1} \mathrm{H}$ NMR [32] and by titration: both techniques gave identical results: DS values between 0.6 and 0.9 were obtained depending on the reaction time for SPEEK; for SPPSU, DS was 2.0 [33,34]. Formulas are reported in Scheme 1.

The procedure for membrane preparation was solution casting using as solvent dimethylsulfoxide (DMSO) or dimethylacetamide (DMAc). In a typical experiment, around $250 \mathrm{mg}$ sample was dissolved in $30 \mathrm{~mL}$ of solvent. The resulting mixture was stirred for $4 \mathrm{~h}$, evaporated to $5 \mathrm{~mL}$, cast onto a Petri dish and heated to dryness for $12 \mathrm{~h}$ at $80^{\circ} \mathrm{C}$. After cooling to room temperature, the resulting membranes (called "standard samples" in the following) were peeled off and treated under dynamic vacuum for $24 \mathrm{~h}$ at $80^{\circ} \mathrm{C}$ for solvent removal. However, a small amount of DMSO remained in the membranes after this step.

A subsequent thermal treatment of SAP membranes was performed at temperatures between 120 and $170^{\circ} \mathrm{C}$, which were chosen after preliminary measurements. The time of thermal treatment was between 48 and $168 \mathrm{~h} \mathrm{[27].}$

X-ray diffraction (XRD) patterns were recorded with a Siemens D5000 diffractometer using $\mathrm{Cu} K \alpha$ radiation $(\lambda=0.1540 \mathrm{~nm})$, steps of $0.04^{\circ}$ and $1 \mathrm{~s}$ step time.

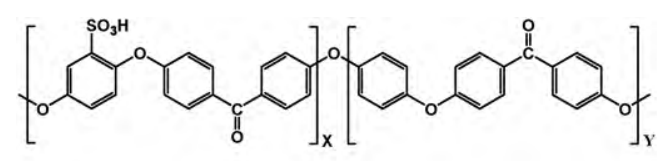

SPEEK

$X=0.6 Y=0.4 D S=0.6 ; X=0.77 Y=0.23 D S=0.77 ; X=0.9 Y=0.1 D S=0.9$

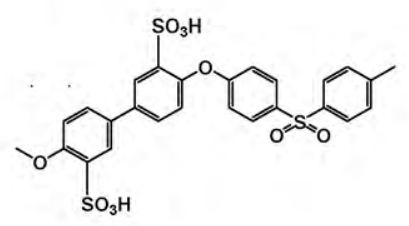

SPPSU

$\mathrm{DS}=2$

Scheme 1. Molecular formula of SPEEK and SPPSU.

\subsection{Stress-strain tests}

The mechanical properties of SPEEK and SPPSU were investigated using an ADAMEL Lhomargy DY30 test machine at room temperature at a constant crosshead speed of $5 \mathrm{~mm} \mathrm{~min}^{-1}$ with aluminium sample holders. Particular attention was given to the macroscopic homogeneity of membranes made by casting and only apparently homogeneous membranes were used for the mechanical tests. The clamping pressure was determined according to a preliminary tensile stress-strain test: it was about $40 \%$ of the apparent elasticity limit, corresponding to the linear part of the tensile curve.

The aluminium sample holders were selected to give rigidity to the clamping system and to optimize the mechanical testing. Fig. 1 shows the shape and geometry of the clamps and specimens used in the uniaxial tensile tests. Fig. 1a presents the membrane of $70 \mathrm{~mm}$ diameter; five rectangular pieces can be cut out with $5 \mathrm{~mm}$ width and $55 \mathrm{~mm}$ length. So, the border of the membranes, where composition may be inhomogeneous, was eliminated by cutting carefully the specimens. Fig. 1b shows the aluminium sample holders and the specimens, which have the same width. On each side $15 \mathrm{~mm}$ of membranes are covered with aluminium clamps, so that the uniaxial tensile properties were measured on membrane samples of about $100 \mu \mathrm{m}$ thickness, $5 \mathrm{~mm}$ width and $25 \mathrm{~mm}$ length.

The selected tensile curves corresponded only to tests with a final rupture in the useful part of the specimens. The other cases of rupture $(<20 \%)$, e.g., near or under grips, were systematically eliminated. Prior to the measurements, the polymer samples were stabilized at ambient temperature and humidity, which was $(50 \pm 10) \%$ RH. The measurement time was below 5 min.

\subsection{Dynamical mechanical analysis (DMA)}

For most polymeric materials the relationship between stress and stain, in the elastic domain, is not linear and they do not obey Hooke's law $(\sigma=E \varepsilon)$, were $E$ is Young's modulus. This modulus is not constant, but is a function of the applied frequency $(f)$. The response of the polymer under a dynamic applied force becomes linearly viscoelastic. Stress and strain are not in-phase and the modulus $E^{*}$ becomes a complex function:

$E^{*}=E^{\prime}+i E^{\prime \prime}$

$E^{\prime}$ and $E^{\prime \prime}$ are the in-phase and out-of-phase components of $E^{*}$.

To improve and characterize the membranes, dynamic mechanical analysis (DMA) was performed on a DMA 2980 apparatus from TA Instruments in extension mode with samples of approximately 


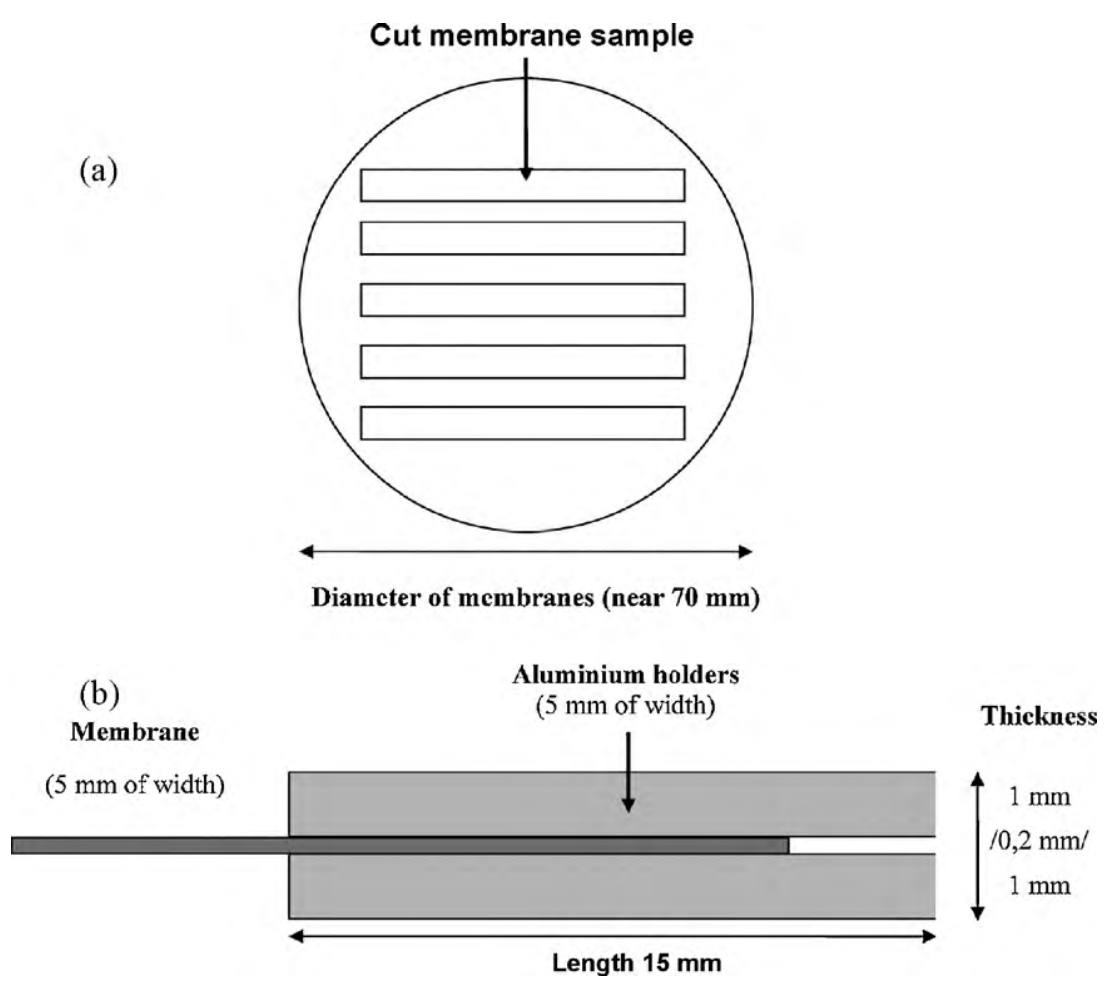

Fig. 1. Representation of samples used in the uniaxial tensile tests. (a) Membrane sample and (b) sample holder.

$15 \mathrm{~mm} \times 7 \mathrm{~mm}$ size and $100 \mu \mathrm{m}$ thicknesses. DMA was operated in air at a fixed frequency $(f)$ of $1 \mathrm{~Hz}$ with $1 \mathrm{~N}$ initial static force and oscillation amplitude of $10 \mu \mathrm{m}$. This last value was chosen to keep the linear viscoelastic domain of samples during experiments. The viscoelastic behaviour of the polymer can be represented by a storage (elastic) part, the storage modulus $E^{\prime}$, and a loss (viscous) part, the loss modulus $E^{\prime \prime}$.

The storage modulus $\left(E^{\prime}\right)$ is in-phase with the applied stress, whereas the loss modulus ( $\left.E^{\prime \prime}\right)$ is out-of-phase. These components $E^{\prime}$ and $E^{\prime \prime}$ represent the real and imaginary components of $E^{*}$ and can be expressed by

$\left|E^{*}\right|=E^{\prime}+i E^{\prime \prime}=\sqrt{\left(E^{\prime}\right)^{2}+\left(E^{\prime \prime}\right)^{2}}$

The loss angle $\delta$, called also damping factor, can be expressed as

$\tan \delta=\frac{E^{\prime \prime}}{E^{\prime}}$

The ratio between the loss and storage modulus is a measure of the amount of deformational energy that is dissipated as heat during each cycle and gives the useful quantity known as the mechanical damping factor.

The storage modulus $\left(E^{\prime}\right)$, loss modulus $\left(E^{\prime \prime}\right)$, and damping $(\tan \delta)$ spectra versus temperature were obtained at a heating rate of $3^{\circ} \mathrm{C} \mathrm{min}^{-1}$ between 50 and $250^{\circ} \mathrm{C}$.

\section{Results}

Fig. 2 represents a typical nominal stress-strain test curve obtained with a SPEEK membrane. The apparent elastic modulus $E$ was determined from the slope of the linear part of the curve, where elastic behaviour of the polymer is observed. The tensile strength TS is taken as the stress value at the maximum of the nominal stress-strain curve and the corresponding strain is indicated. Ductility is expressed as percentage of total elongation at fracture TEL. The average mechanical parameters obtained from stress-strain measurements are reported in Table 1 for different SAP. Elastic modulus is generally above $1 \mathrm{GPa}$, with tensile strengths in the order of $25-80 \mathrm{MPa}$. The yield point is below $10 \%$ in all cases and elongation at fracture varies greatly with values between 7 and $50 \%$. These values are typical of polymers below their glass transition temperature. The performed thermal treatments generally increase the elastic modulus and tensile strength of the membranes and reduce ductility. This is consistent with the strong enhancement of glass transition temperature observed by DMA. Comparing polymers with similar heat treatment, but different DS, one notices that the polymer with the larger DS shows a lower ductility but higher strength, certainly due to the stronger intermolecular forces between macromolecular chains by a greater amount of hydrogen bonds.

Figs. 3 and 4 show typical DMA curves of various SPEEK membranes: storage modulus and $\tan \delta$ (loss angle) are represented versus temperature. These representations allow determination of the glass transition temperature of the SAP, which is characterized by a decrease of storage modulus and peak of $\tan \delta$ curve. In our case, the major part of samples becomes very soft during glass transition

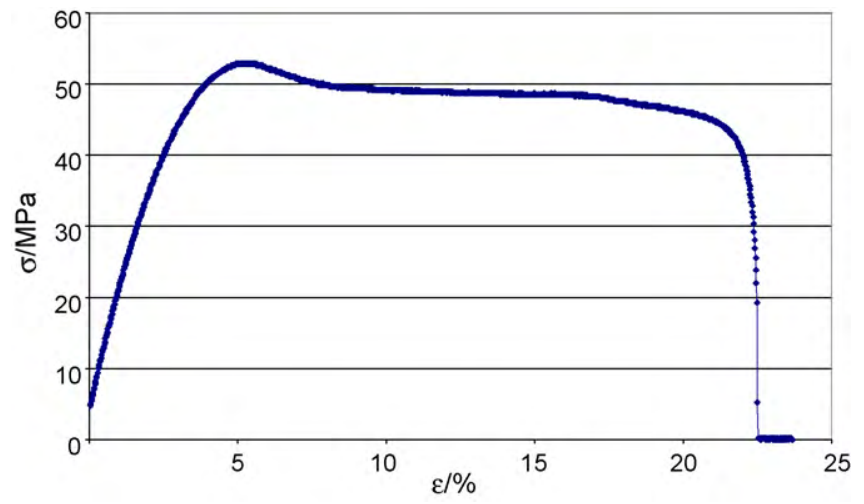

Fig. 2. Typical nominal stress-strain curve for a SPEEK (0.9) membrane heated at $140^{\circ} \mathrm{C}$. 
Table 1

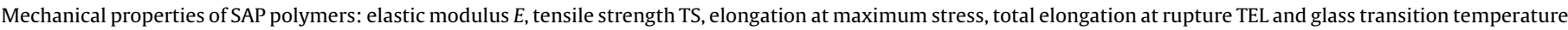

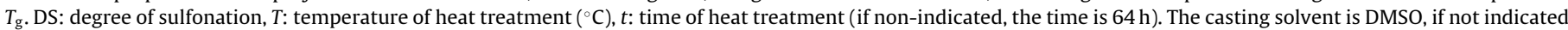
otherwise.

\begin{tabular}{|c|c|c|c|c|c|}
\hline Polymer & $E(\mathrm{MPa})$ & TS (MPa) & Elongation at maximum stress (TS) (\%) & TEL (\%) & $T_{\mathrm{g}}\left({ }^{\circ} \mathrm{C}\right)$ \\
\hline \multicolumn{6}{|l|}{ Name, DS, $T(t)$} \\
\hline SPEEK 0.9, $160+120$ & $2305 \pm 250$ & $75 \pm 5$ & $8 \pm 1$ & $10 \pm 3$ & \\
\hline SPEEK 0.9, 160 & $2020 \pm 170$ & $64 \pm 8$ & $7 \pm 1$ & $17 \pm 10$ & $205 \pm 5$ \\
\hline SPEEK 0.9, 140 & $1760 \pm 40$ & $58 \pm 4$ & $6 \pm 1$ & $22 \pm 10$ & $190 \pm 5$ \\
\hline SPEEK 0.9, 120 (168 h) & $1590 \pm 260$ & $56 \pm 7$ & $5 \pm 1$ & $27 \pm 10$ & \\
\hline SPEEK 0.9 & $1010 \pm 80$ & $32 \pm 1$ & $5 \pm 1$ & $7 \pm 1$ & $105 \pm 2$ \\
\hline SPEEK 0.9 DMAC & $680 \pm 220$ & $25 \pm 1$ & $5 \pm 1$ & $7 \pm 1$ & $110 \pm 2$ \\
\hline SPEEK $0.75,140$ & $1240 \pm 120$ & $43 \pm 4$ & $7 \pm 1$ & $29 \pm 13$ & \\
\hline SPEEK 0.6, $120(168 \mathrm{~h})$ & $1410 \pm 240$ & $34 \pm 9$ & $5 \pm 2$ & $48 \pm 10$ & \\
\hline SPEEK 0.6, 120 (48 h) DMAc & $1500 \pm 240$ & $52 \pm 8$ & $6 \pm 2$ & $26 \pm 6$ & \\
\hline SPEEK 0.6 DMAC & $1200 \pm 250$ & $36 \pm 8$ & $6 \pm 1$ & $12 \pm 2$ & $130 \pm 2$ \\
\hline SPPSU 2.0170 & $2950 \pm 300$ & $81 \pm 3$ & $4 \pm 1$ & $7 \pm 3$ & $215 \pm 5$ \\
\hline Nafion [33] & 25 & 25 & - & 300 & $120 \pm 5$ \\
\hline Nafion [5] & 33 & & & 500 & \\
\hline
\end{tabular}

and stretches out dramatically. So, the second part of the $\tan \delta$ peak and the rubbery plateau of storage modulus cannot be monitored. The glass transition temperature $\left(T_{\mathrm{g}}\right)$ has therefore been taken as the onset point of increasing $\tan \delta$ (Table 1 ) [35].

Figs. 3 and 4 show impressively the important change of glass transition temperature, from $105^{\circ} \mathrm{C}$ to about $205^{\circ} \mathrm{C}(\mathrm{DS}=0.9)$ and from 125 to $210^{\circ} \mathrm{C}$ ( $\mathrm{DS}=0.6$ ), observed after thermal treatment ("annealing") of SPEEK membranes. It is evident that this change is of major importance for intermediate temperature fuel cell appli-

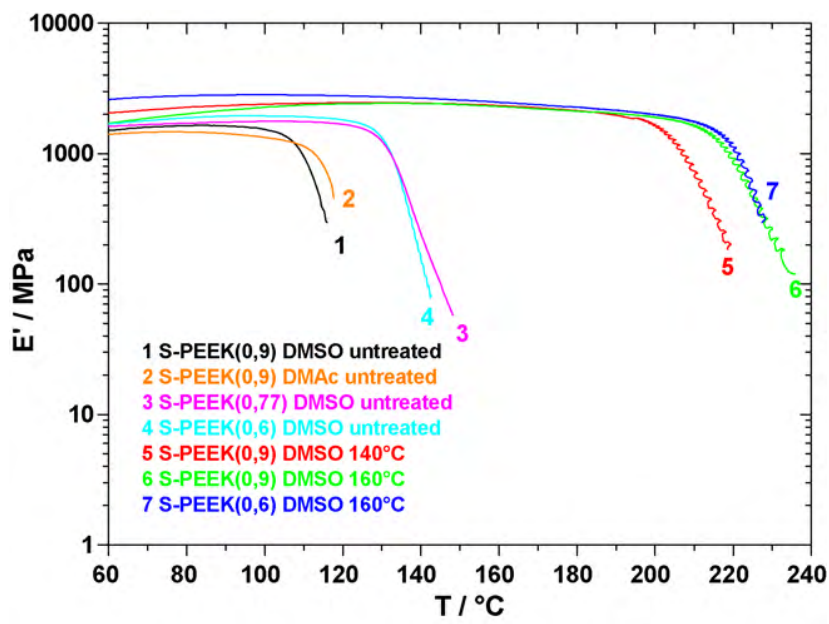

Fig. 3. Storage modulus of various SPEEK membranes as function of temperature from DMA experiments.

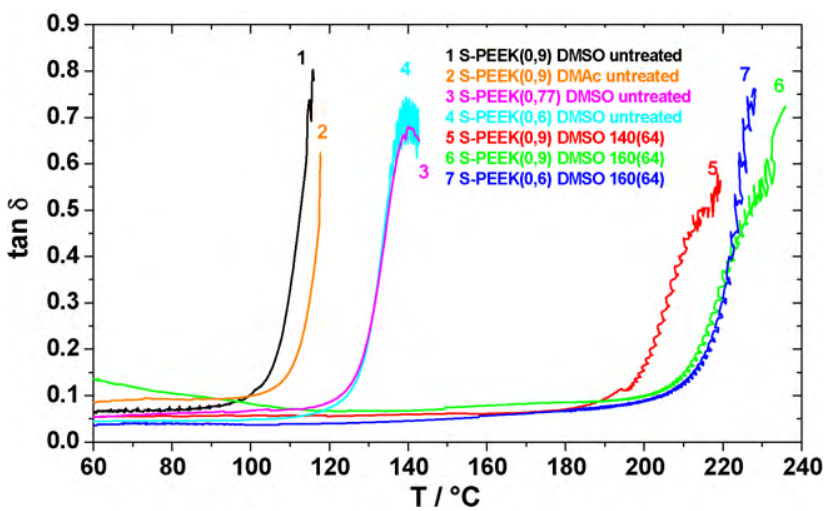

Fig. 4. Tangent delta of various SPEEK membranes as function of temperature from DMA experiments. cation, since $T_{\mathrm{g}}$ values as well as Young's modulus strongly depend on thermal treatment (Fig. 5). The $T_{\mathrm{g}}$ is higher for the polymer with lower degree of sulfonation (DS), in agreement with literature for several polymer membranes [29,31]. This result has been also reported for SPEEK membranes by solid state NMR measurements [36]. Here, whatever the initial sample DS (0.6 or 0.9$), T_{g}$ reaches approximately similar values after thermal treatment. We have previously shown that annealing of SAP membranes at $160^{\circ} \mathrm{C}$ leads to cross-linking between macromolecular chains and a significant reduction of DS is observed, which falls to 0.66 for an initial $\mathrm{DS}=0.9$ and to 0.45 for an initial DS $=0.6$ [27]. At $140^{\circ} \mathrm{C}$, crosslinking, if present, is only marginal; the effect on curve 5 is probably related to irreversible conformational changes, as observed in PEEK [37].

Fig. 3 presents the variation of storage modulus $\left(E^{\prime}\right)$ with temperature for SPEEK membranes without and with annealing. The slight increase of storage modulus $\left(E^{\prime}\right)$ up to about $100^{\circ} \mathrm{C}$ corresponds to removal of some residual casting solvent (DMSO or DMAc) and water, which have a plasticizing effect $[28,36]$. The strong increase of $T_{\mathrm{g}}$ after annealing can be observed as well on storage modulus and on $\tan \delta$ (Fig. 4). While $T_{\mathrm{g}}$ depends on DS above 0.77 (curves 1,3 , and 4 ), below that concentration there is no apparent effect, indicating that under a certain concentration of sulfonic acid groups, the glass transition does not depend on DS (curves 5,6, and 7).

Comparing curves 1 and 2 in Figs. 3 and 4, one can see the influence of the casting solvent, DMSO or DMAc. In fact, very little difference is observed with both solvents; $T_{\mathrm{g}}$ with DMAc as casting solvent is slightly higher than for DMSO.

Figs. 6 and 7 show, respectively, storage modulus and $\tan \delta$ curves for untreated and annealed at $170{ }^{\circ} \mathrm{C}$ SPPSU samples. One observes again the slight increase of storage modulus due to

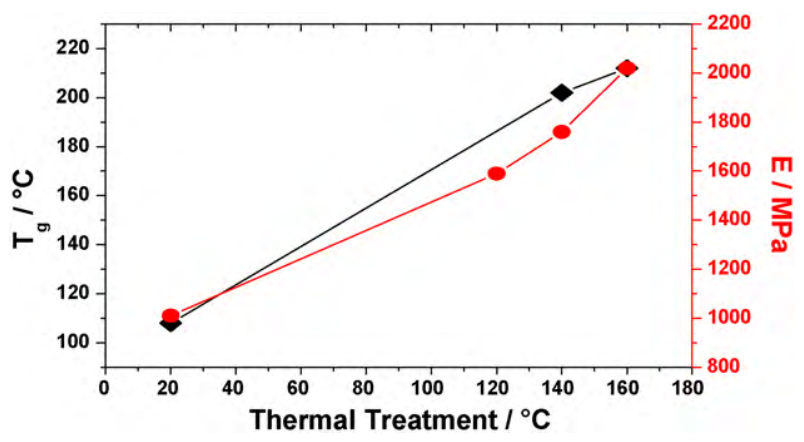

Fig. 5. Glass transition temperatures (from DMA) and elastic moduli (from stress-strain tests) of SPEEK ( $D S=0.9$ ) membranes versus temperature of thermal treatment. 


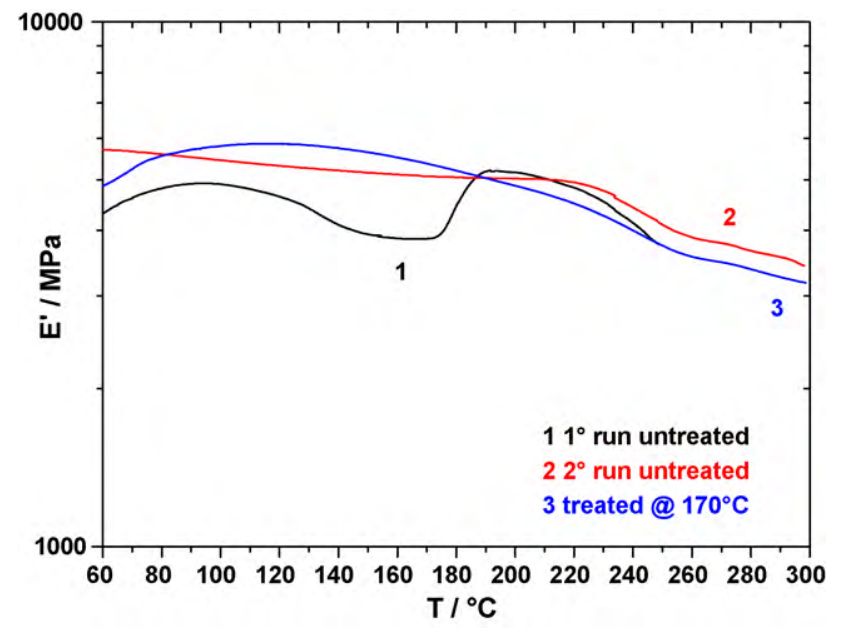

Fig. 6. Storage modulus of SPPSU membranes as function of temperature.

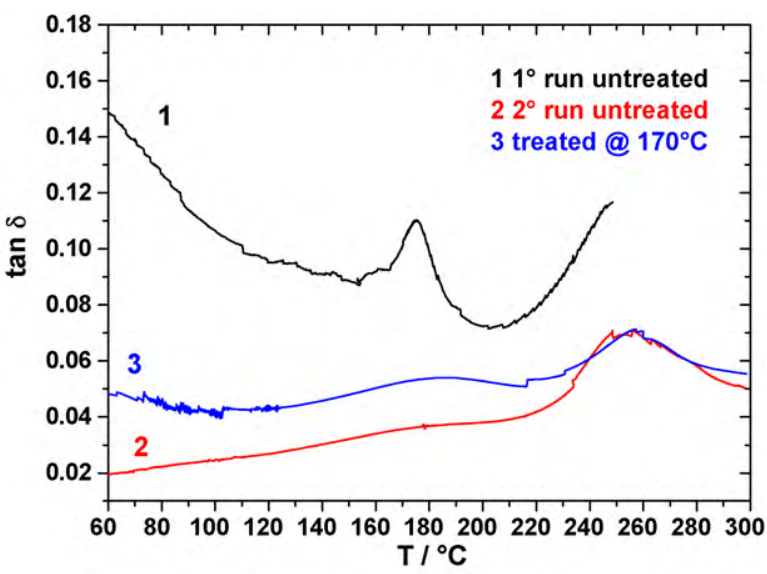

Fig. 7. Tangent delta of SPPSU membranes as function of temperature.

loss of plasticizers and the very high glass transition temperature above $210^{\circ} \mathrm{C}$. Some very interesting features can be observed, which are characteristic of an in situ curing of the membranes and formation of cross-links between macromolecules [27]. The first heating (curve 1 - first run) shows a glass transition temperature above $160^{\circ} \mathrm{C}$. Following this transition, storage modulus increases again and a second peak above $210^{\circ} \mathrm{C}$ is observed (Fig. 7). This behaviour can be explained by "in situ" cross-linking, which leads to an increase of storage modulus (Fig. 6) and a shift of the glass transition to much higher temperature. Consistent with this explanation, the $\tan \delta$ peak and lowering of storage modulus above $210^{\circ} \mathrm{C}$ are also observed at following DMA scans (curve $2-$ second run) of the same membrane, but the peak above $160^{\circ} \mathrm{C}$ has disappeared. Previous experiments on SPPSU membranes showed that cross-linking is observed at $170^{\circ} \mathrm{C}$ during isothermal annealing; this temperature range is compatible with that observed in DMA.

\section{Discussion}

Mechanical properties of polymers depend on many parameters, including degree of crystallinity, presence of plasticizers and cross-linking. Their discussion is complex and intricate. The different parameters will now be discussed separately, but it is well understood that their interplay is essential for understanding the complex properties.

\subsection{Crystallinity}

Increasing the crystallinity of a polymer generally enhances its elastic modulus and tensile strength and reduces its ductility. The SAP samples studied here are, however, fully amorphous, whatever the preparation and annealing treatments performed [22,27]. No crystalline amounts were found within the detection limits of XRD, performed routinely on the polymer samples. This parameter can thus be excluded.

\subsection{Plasticizers}

Plasticizers are small molecules, such as residual solvents, which are inserted between macromolecular chains and weaken the intermolecular forces between them [4]. In the case of sulfonated aromatic polymers, different intermolecular interactions can be discussed: the strongest are hydrogen bonds, acting especially between sulfonic acid groups, but some others are present including permanent dipole-dipole interactions, such as ketone-ketone and sulfone-sulfone group interactions. Furthermore, weak London-type interactions between aromatic backbones have also to be discussed. The presence of residual water and DMSO (DMAc) molecules, which are high dielectric constant solvents, will particularly weaken the hydrogen bonds and dipole interactions and have certainly a strong plasticizing effect. In fact, the removal of residual solvent is seen in the increase of storage modulus up to $100{ }^{\circ} \mathrm{C}$ observed in the DMA curves.

\subsection{Influence of chemical constitution}

Below the glass transition temperature, the storage modulus values observed by DMA are fully consistent with the elastic modulus data obtained from stress-strain tests (Table 1), which are typically above $1 \mathrm{GPa}$, with tensile strengths in the order of $20-80 \mathrm{MPa}$. The elasticity is attributable to temporary and reversible deformation of valence angles along the macromolecular backbone that is changes of conformation. Fracture corresponds to irreversible break of covalent bonds inside the macromolecule chains. The plastic domain is short; large plastic domains are mainly observed for macromolecules with linear chains, held together by weak Van der Waals forces and which can easily glide parallel to the chains, so that a sort of viscous flow is possible. Calculations of preferred macromolecular conformation of SPEEK show that a spherical shape is preferred, due to intra-chain hydrogen bonds. It is well known that formation of spheroids generally strengthens polymers, so that the relatively high elastic modulus and tensile strengths of SAP polymers are understandable.

In order to have useful mechanical properties for applications, one should avoid the temperature domain, where viscoelastic behaviour is observed, that is around the glass transition temperature. In order to increase the glass transition temperature, cross-linking of polymer chains is an important tool, because the bridges between macromolecules impede the chain gliding and retard the glass transition. On the other hand, a too high degree of cross-linking leads to a too hard and fragile polymer, which does not incorporate enough water to have sufficiently high proton conductivity. The cross-linking reaction between SPPSU chains is actually observed in situ during the DMA experiment, as shown in Figs. 6 and 7, as evidenced by a sudden increase of storage modulus above $160^{\circ} \mathrm{C}$. The glass transition temperature changes strongly between the first and subsequent DMA scans.

\section{Conclusion}

The analysis of mechanical properties of proton-conducting SAP membranes by stress-strain tests and DMA show a very impor- 
tant effect of thermal treatments performed on the membranes after solvent casting, with a large increase of glass transition temperature and mechanical strength. The DMA gives important complementary insight: removal of residual casting solvent, which acts as plasticizer, leads in all cases to an increase of storage modulus. In the case of SPPSU, the cross-linking reaction can be observed in situ.

Considering the importance of glass transition temperature and mechanical properties for operation of fuel cell membranes, it is clear that thermal treatment appears as a very powerful promising tool for membrane optimization. Based on these conclusions, SAP polymer membranes deemed of low importance for PEM fuel cell application should be re-considered carefully.

\section{Acknowledgments}

The authors thank the Franco-Italian University for a thesis grant (Vinci program 2006) and the Italian Ministry of University and Research for financial support (PRIN 2007 project).

\section{References}

[1] W.D. Callister, Fundamentals of Materials Science and Engineering, 2nd ed. Wiley, 2005.

[2] S.J. Picken, D.P.N. Vlasveld, H.E.N. Bersee, C. Özdilek, E. Mendes, in: P. Knauth, J Schoonman (Eds.), Nanocomposites: Ionic Conducting Materials and Structural Spectroscopies, Springer, 2008.

[3] J. Philibert, A. Vignes, Y. Bréchet, P. Combrade, Métallurgie Mécanique, 2nd ed., Dunod, Paris, 2002.

[4] G. Champetier, L. Monnerie, Introduction à la Chimie Macromoléculaire, Masson, Paris, 1969, p. 470.

[5] G. Alberti, R. Narducci, M. Sganappa, Journal of Power Sources 178 (2008) 575

[6] M.B. Satterfield, J.B. Benziger, Journal of Polymer Science Part B-Polymer Physics 47 (2009) 11.

[7] P.W. Majsztrik, A.B. Bocarsly, J.B. Benziger, Macromolecules 41 (2008) 9849.

[8] Y.D. Premchand, M.L. Di Vona, P. Knauth, Nanocomposites: Ionic Conducting Materials and Structural Spectroscopies, Springer, 2008.

[9] J.D. Ferry, Viscoelastic properties of polymers. 3rd ed. New York, Wiley, 1980.

[10] N.G. McCrum, B.E. Read, G. Williams, Anelastic and Dielectric Effects in Polymeric Solids, Wiley and Sons, London, 1967.
[11] L.C.E. Struik, Physical Aging in Amorphous Polymers and Other Materials, Elsevier, Amsterdam, 1978.

[12] G.G. Scherer, (Ed.), Fuel Cells I, Adv. Polym. Sci., Volume 215, Springer, BerlinHeidelberg, 2008

[13] M.L. Di Vona, D. Marani, A. D’Epifanio, E. Traversa, M. Trombetta, S. Licoccia, S. Caldarelli, P. Knauth, Solid State Ionics 2004835 (2005) 235.

[14] T. Astill, Z. Xie, Z.Q. Shi, T. Navessin, S. Holdcroft, Journal of the Electrochemical Society 156 (2009) B499.

[15] T.J. Peckham, J. Schmeissert, S. Holdcroft, Journal of Physical Chemistry B 112 (2008) 2848.

[16] M.L. Di Vona, D. Marani, A. D’Epifanio, S. Licoccia, I. Beurroies, R. Denoyel, P. Knauth, Journal of Membrane Science 304 (2007) 76.

[17] D. Marani, M.L. Di Vona, E. Traversa, S. Licoccia, I. Beurroies, P.L. Llewellyn, P. Knauth, Journal of Physical Chemistry B 110 (2006) 15817.

[18] P. Knauth, M.L. Di Vona, Proceedings of the 6th International IEEE Conference on Polymers and Adhesives in Microelectronics and Photonics, 2007, p. 257.

[19] M.L. Di Vona, S. Licoccia, P. Knauth, Solid State Ionics 179 (2008) 1161.

[20] R.C. Jiang, H.R. Kunz, J.M. Fenton, Journal of Power Sources 150 (2005) 120

[21] E. Sgreccia, M. Khadhraoui, C. de Bonis, S. Licoccia, M.L. Di Vona, P. Knauth, Journal of Power Sources 178 (2008) 667.

[22] E. Sgreccia, M.L. Di Vona, S. Licoccia, M. Sganappa, M. Casciola, J.F. Chailan, P. Knauth, Journal of Power Sources 192 (2009) 353.

[23] L. Chikh, S. Girard, D. Teyssie, O. Fichet, Journal of Applied Polymer Science 107 (2008) 3672.

[24] M.L. Di Vona, D. Marani, C. D’Ottavi, M. Trombetta, E. Traversa, I. Beurroies, P. Knauth, S. Licoccia, Chemistry of Materials 18 (2006) 69.

[25] A. Reyna-Valencia, S. Kaliaguine, M. Bousmina, Journal of Applied Polymer Science 99 (2006) 756

[26] E.K. Pefkianakis, V. Deimede, M.K. Daletou, N. Gourdoupi, J.K. Kallitsis, Macromolecular Rapid Communications 26 (2005) 1724.

[27] M.L. Di Vona, E. Sgreccia, S. Licoccia, G. Alberti, L. Tortet, P. Knauth, Journal Physical Chemistry B 113 (2009) 7505.

[28] S. Kundu, L.C. Simon, M. Fowler, S. Grot, Polymer 46 (2005) 11707.

[29] Z.W. Bai, M.D. Houtz, P.A. Mirau, T.D. Dang, Polymer 48 (2007) 6598.

[30] A. Navarro, C. del Rio, J.L. Acosta, Journal of Membrane Science 300 (2007) 79.

[31] P. Chhabra, V. Choudhary, European Polymer Journal 45 (2009) 1467.

[32] S.M.J. Zaidi, S.D. Mikhailenko, G.P. Robertson, M.D. Guiver, S. Kaliaguine, Journal of Membrane Science 173 (2000) 17.

[33] M.L. Di Vona, A. D’Epifanio, D. Marani, M. Trombetta, E. Traversa, S. Licoccia, Journal of Membrane Science 279 (2006) 186.

[34] M.L. Di Vona, L. Luchetti, G.P. Spera, E. Sgreccia, P. Knauth, Comptes Rendus Chimie 11 (2008) 1074

[35] K. Backfolk, R. Holmes, P. Ihalainen, P. Sirvio, N. Triantafillopoulos, J. Peltonen, Polymer Testing 26 (2007) 1031.

[36] Y. Paik, S.A. Chae, O.H. Han, H.S. Youp, H.H. Yong, Polymer 50 (2009) 2664.

[37] Z.Y. Zhang, H.M. Zeng, Polymer 34 (1993) 3648. 